

\title{
Low back pain among hospital workers in Kano, North-west Nigeria
}

\section{Abubakar MK*1, Rabiu A², Ibrahim MU1, Musa KA1, Muhammad S1, Mamuda AA ${ }^{1}$}

1Department of Surgery, ${ }^{2}$ Department of Obstetrics and Gynecology, Bayero University Kano/Aminu Kano Teaching Hospital, P.M.B. 3011, Kano, Kano State.

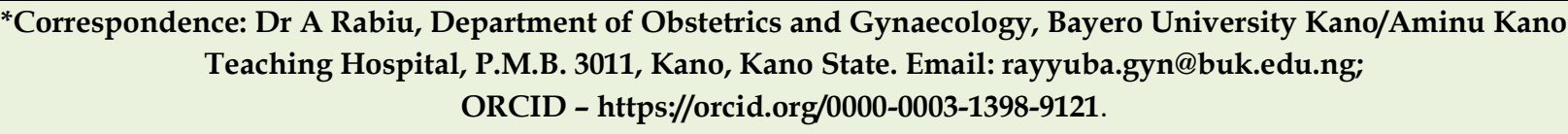

\begin{abstract}
Background: About $90 \%$ of individuals will experience back pain at one point or the other in their lives. Hospital workers are considered to have a considerable risk of developing low back pain.

Objective: To determine the prevalence and risk factors for low back pain among health workers in tertiary hospitals in Kano, Nigeria.

Methods: The study was a cross-sectional survey. A questionnaire was designed and administered to 200 personnel of the teaching hospitals in Kano. Socio-demographic characteristics, presence of low back pain, factors that relieve and aggravate the low back pain and relationship of back pain and work activities, were recorded on the questionnaire.

Results: The mean age of the respondents was 33.4 \pm 7.08 years. Sixty-six per cent of the respondents had back pain within a year of the study. There was a $29 \%$ point prevalence of low back pain among the respondents. Statistically significant association was established between various activities such as prolonged sitting and walking and pain in the lower back $(p=0.000)$. There was an association between low back pain and the type of job (department) of the respondents $(p=0.016)$. The dull ache was the predominant presentation $(58 \%)$ followed by piercing and gripping in $20 \%$ and $19 \%$ respectively. Prolonged sitting was the main aggravating factor, while numbness was the main feature of referral in $18 \%$. Only $5.0 \%$ of the respondents used medications for their back pain.

Conclusion: Low back pain is common among hospital workers with a point prevalence of $29.1 \%$. About $25 \%$ had low back pains that prevented participated in normal duty. Majority of the respondents believed back pain is preventable.
\end{abstract}

Keywords: Hospital Workers, Low back pain, Nigeria, Prevalence, Risk factors.

\section{Introduction}

Low back pain is one of the common complaints that present to the clinician. It has been reported that $40-90 \%$ of individuals will experience back pain at one point or another in their lifetime. [1-3] A review done in Nigeria found a 12-month prevalence of $32.5-73.53 \%$ for low back pain. 
[4] In another study done in the US, where they studied civilian and non-institutionalized population, the prevalence of low back pain was $25.7 \%$ for all workers, $24.5 \%$ for males, $27.1 \%$ for females, $23.8 \%$ for younger workers and $27.7 \%$ for older workers. ${ }^{[5]}$ Among the working class, especially those in white-collar jobs, low back pain is one of the common reasons for absenteeism. ${ }^{[6]}$ Health workers are particularly at risk of low back pain, especially the nurses. $[3,7,8]$

Multiple factors, especially the type and nature of work, influence the development and incidence of low back pain. For this reason, a study was conducted among workers who earned low wages among hotel housekeepers to look at work-related risk factors and the study identified tasks that require reaching/overstretching as main risk factors for low back pain. Such workers were found to have 2.93 higher odds of having low back pains than those who did not partake in similar activities at work. Moreover, people whose job requires repetitive bending had $97 \%$ increased odds of having low back pain than those whose task did not require bending. [9]

Physical activities like lifting or transfer of patients, sudden movement, and poor posture have all been recognised to cause low back pain. [9]

Low back pain affects patients in several ways. It can cause psychological burden, physical disability, financial challenge, absenteeism and inter- as well as intra-professional disharmony. [10] Healthcare personnel have been reported to have a higher risk of low back pain, more so, in the resource-poor settings. This is partly because of the lack of knowledge of preventable measures, poor supporting equipment coupled with exposure to work-related risk factors. Some researchers have looked at the prevalence and risk factors for low back pain among health workers in North-western Nigeria. Awosan et al.[11] studied the prevalence, perception and correlates of low back pain among healthcare workers in tertiary health institutions in Sokoto, north-west Nigeria. They reported a high prevalence of low back pain which was associated with older age and female sex, working for over 10 years, overweight/obesity, and lifting heavy objects/patients at work, as the major factors predisposing to low back pains.

This study was conducted to determine the prevalence and risk factors for low back pain among health workers in tertiary hospitals in Kano, Nigeria.

\section{Methods}

This was a cross-sectional survey that was conducted among health workers at three tertiary health institutions in Kano city (Aminu Kano Teaching Hospital, Murtala Mohammad Specialist Hospital, and Mohammad Abdullahi Wase Specialist Hospital). The survey was carried out from $1^{\text {st }}$ January to $31^{\text {st }}$ June 2017. A list of all the tertiary health institutions was made out of which three institutions were selected using a Random Number Generator. Ethical approval was obtained from the relevant authorities within the institutions. Informed consent was obtained from eligible healthcare workers at these institutions. The health workers included doctors, nurses, clinical assistants, administrative staff, physical therapists, technicians and medical record staff.

A self-administered, pre-tested questionnaire was used for data collection. Information such as socio-demographic characteristics, the occurrence of low back pain within the last one year, nature of low back pain, employment history, years in services, nature of routine duties, use of medications for low back pain and history of absenteeism from work because of 
low back pain were recorded on the questionnaire.

The data obtained were coded and analyzed using the Statistical Package for Social Sciences (SPSS) version 24. The data were summarized using frequency, percentages, means, median, and standard deviations. The Chi-Squared test was used to determine associations between low back pain, socio-demographic characteristics and physical activities. The level of significance was set as $P<0.05$.

\section{Results}

Out of the 200 questionnaires that were administered to the health workers at the study locations, only 141 completed questionnaires were retrieved. The retrieval rate was $70.5 \%$. The age range was 22-50 years; the mean age of the respondents was $33.4 \pm 7.08$ years with a median age of 32 years. Most of the respondents were males $(89 ; 63.1 \%)$ while females comprised 52 (36.9\%). Ninety-three (66\%) respondents have had low back pain within one year of the study and a point prevalence of $29.1 \%(41 / 141)$.

Most of the respondents were in the age group of $30-34$ years $(40 ; 28.4 \%)$ followed by the $25-29$ years group (30; $21.3 \%)$. Seventy-four (52.5\%) had tertiary level of education as shown in Table I. A large proportion of the respondents (98; $69.5 \%$ ) was married and had a normal Body Mass Index (BMI) (92; 65.2\%).

The distribution of the respondents across the institutions showed $47.0 \%$ in Aminu Kano Teaching Hospital, whereas Murtala Muhammad Specialist Hospital and Abdullahi Muhammad Wase Specialist Hospital had 37.0\% and $16.0 \%$ respectively. The distribution of the respondents across departments/units revealed $64(45 \%)$ in the nursing department, 14 (9.9\%) in
Family Medicine department and 13 (9.2\%) in Surgery department (Table II).

The majority of the respondents described pains of dull ache nature $(58.0 \%)$, while others described the pain as piercing $(20.0 \%)$, gripping $(19.0 \%)$ and burning $(10.0 \%)$. Some of the identified activities that aggravated low back pain included prolonged sitting and walking as shown in Table III. Also, bed rest was the most important factor for relief followed by the use of medications. The point prevalence of medication use among the respondents was 5.0\%. Eighteen $(12.8 \%)$ of the respondents had a history of numbness on the lower limbs.

Twenty-seven (19.2\%) respondents had a history of back pain that prevented them from carrying out their duties at the time of survey while 6 $(4.3 \%)$ respondents had been previously hospitalized for low back pain. One hundred and nine $(77.3 \%)$ respondents thought low back pain was preventable while $14(9.9 \%)$ thought low back pain was not preventable. Eighteen $(12.8 \%)$ respondents did not know whether back pain was preventable or not and 133 (94.3\%) respondents had previously received educational talk on how to prevent low back pain.

\section{Discussion}

The prevalence of low back pain was found to be $65.9 \%$. This falls within the lifetime prevalence of $11 \%$ to $84 \%$ reported by Walker. [12] However, the prevalence of low back pain in low-income countries is estimated to be at $18.0 \%$ and lower than $30.0 \%$ in high-income countries. ${ }^{[12]}$ In a study done by Usman et al among pregnant women in Kano with low back pain and pelvic girdle pain, prevalence rates of $34.3 \%$ and $57.6 \%$ respectively were reported. [13] 
Table I: Socio-demographic characteristics of the respondents

\begin{tabular}{lll}
\hline Characteristics & Frequency & Percentage \\
\hline Age group (Years) & 13 & 9.2 \\
$20-24$ & 30 & 21.3 \\
$25-29$ & 40 & 28.4 \\
$30-34$ & 28 & 19.9 \\
$35-39$ & 18 & 12.8 \\
$40-44$ & 9 & 6.4 \\
$45-49$ & 3 & 2.1 \\
$50-55$ & & \\
Educational status & 13 & 9.2 \\
Primary & 54 & 38.3 \\
Secondary & 74 & 52.5 \\
Tertiary & & \\
Marital status & 98 & 69.5 \\
Married & 36 & 25.5 \\
Single & 7 & 5.0 \\
Divorced & & \\
Body Mass Index (Kg/m $\left.\mathbf{m}^{2}\right)$ & 18 & 12.8 \\
Underweight (<18.5) & 92 & 65.2 \\
Normal (18.5-24.9) & 26 & 18.4 \\
Overweight (25-29.9) & 1 & .7 \\
Obesity I (30-34.9) & 1 & .7 \\
Obesity II (35-39.9) & 3 & 2.1 \\
Morbid ( $\geq 40)$ & &
\end{tabular}

Table II: Distribution of the respondents according to their departments

\begin{tabular}{lll}
\hline Department & Frequency & Percentage \\
\hline Nursing & 64 & 45.4 \\
Surgery & 13 & 9.3 \\
Family Medicine & 14 & 9.9 \\
Internal Medicine & 7 & 4.9 \\
Obstetrics \& Gynaecology & 7 & 4.9 \\
Paediatrics & 7 & 4.9 \\
Physiotherapy & 6 & 4.3 \\
Ear-Nose-Throat & 6 & 4.3 \\
Administration & 7 & 4.9 \\
Others & 10 & 7.1 \\
Total & 141 & 100.0 \\
\hline
\end{tabular}


Table III: Frequency of factors which aggravate or relief low back pains

\begin{tabular}{llll}
\hline Factors affecting pain & & Frequency & Percentage \\
\hline Aggravating Factors & Walking & 16 & 22.5 \\
& Sitting and standing & 11 & 15.5 \\
& Standing and & 7 & 9.9 \\
bending & & \\
& Lifting & 9 & 12.7 \\
& Moving & 8 & 11.3 \\
& Sitting alone & 18 & 25.4 \\
& Bending and lifting & 2 & 2.8 \\
& Total & 71 & 100.0 \\
Relieving Factors & & \\
& Physiotherapy & 21 & 13.1 \\
& Bed rest & 91 & 56.9 \\
& Warm compress & 7 & 4.4 \\
& Medications & 41 & 25.6 \\
& Total & 160 & 100.0 \\
\hline
\end{tabular}

Responses are not mutually exclusive in both aspects of the response

A point prevalence of $29.1 \%$ was observed in this study. The finding is similar to the report in most studies done on the subject matter. $[1,2,7,15]$ However, the prevalence in Kano is lower than the worldwide prevalence of low back pain attributable to an occupation which is $37.0 \%$. [16]

The prevalence of low back pain was higher among the age group of 30-39 years (28.4\%). This is similar to the previous report by Sikiru and Hanifa [7] which reported a prevalence of $73.5 \%$. The frequency of low back pain was highest among nurses constituting $67.8 \%$ of all the respondents with low back pain. There was a significant association between type of job represented by the department to which the respondents belonged and low back pain. This observation is similar to the findings in other studies that were conducted among hospital workers. [3, 15, 17, 18] The observed point prevalence is similar to the figure earlier reported by Sanya and colleague. [18] This indicates that back pain occurs at different times among individuals. Up to $54.2 \%$ of the respondents described their low back pain as a dull ache. This may be because mechanical back pain which is the commonest type of back pain is mostly dull and none radiating. Like similar studies, this study found an association between low back pain and activities like bending, lifting and prolonged standing. [3,7,15,17,18]

Only $12.8 \%$ of the respondents had a history of lower limb weakness or numbness. Radicular back pain is not very common. This figure is lower than $23 \%$ and $26.2 \%$ reported by Keriri. [19] Only 38. $7 \%$ had relief of their pains with medications compared $61.3 \%$ who experienced no relief with any form of medication. Physiotherapy was observed to give some relief in $22.6 \%$ of the respondents. Omokhodion et al. ${ }^{[3]}$ in a study of the prevalence of low back pain among the staff in a rural hospital in Nigeria, reported that $29 \%$ of the respondents took some rest to relieve their pain while $70 \%$ treated their low back pain with analgesics. There was no mention of physiotherapy in the listed treatment options. However, Sikiru and Hanifa [7] conducted a similar study among nurses in a Nigerian hospital and observed $27 \%$ of the respondents with low back pain used physiotherapy services. Keriri [19] in Taif, Saudi 
Arabia in a similar study among nurses in operating rooms, reported that $75.4 \%$ of the participants used bed rest as a treatment modality. Other modalities reported included muscle relaxant $(11.5 \%)$ and analgesics $(13.1 \%)$. [19] The findings in the present study agreed with most studies that indicated the benefit of physiotherapy and the use of analgesics in the management of low back pain. [3, 7, 19] Bed rest seems to be the most reliable modality for the relief of low back pain and pelvic girdle pain in about $85.9 \%$ of cases. This is similar to the findings of Keriri (75.4\%) ${ }^{[19]}$ in Taif, Saudi Arabia.

Despite a relatively high prevalence of low back pain among hospital workers, only $19.2 \%$ had pain that was severe enough to prevent them from carrying out their duties. Twenty-six per cent of the respondents had a history of hospitalization due to their back pain. This was quite lower than $54.4 \%$ reported by Al-Dajah [20] among nurses in Suydar region, Riyadh, Saudi Arabia. Up to $22 \%$ of the respondents had obtained excused duty on account of low back pain. This is quite close to $35.6 \%$ reported by Sikiru and Hanifa ${ }^{[7]}$ among nurses in a Nigerian hospital but higher than $8.1 \%$ reported by Sanya and colleagues [18] among hospital workers in Ibadan, south-western Nigeria.

The majority $(56.0 \%)$ of the respondent in the present study thought that low back pain was related to activities. This is similar to the findings in studies earlier conducted in Nigeria by Omokhodion and colleagues (40.\%) and Sikiru and Hanifa $(66.67 \%)$ [3,7 but higher than 23\% reported in Cape Town, South Africa. [21] Most respondents had received at one time or the other, educational talks on how to lift objects, sit, or stand to prevent low back pain. However, despite their knowledge, though the study did not evaluate the application of the acquired knowledge, correct application of preventive measures of low back pain was doubtful.

The cross-sectional design of the study, the nonclinical assessment of the severity of low back pains among those who had it at the time of the study are limitations to the study. From the findings, adherence of health workers to all the preventive measures such as back and aerobic exercises, back education, use of mechanical support like a corset, ergonomic interventions at workplace and modification of the various risk factors are recommended as earlier highlighted. [22,23]

\section{Conclusion}

Low back pain is common among healthcare personnel and can be the reason for absenteeism. The majority of health workers belief low back pain is preventable. Identifiable risk factors for low back pain are mainly activity-related like prolonged sitting and walking.

Authors' Contributions: AMK and RA conceived and designed the study. AMK, IMU, MKA and SM participated in data collection and analysis. RA and MAA drafted the manuscript and critically revised the manuscript for intellectual content. All the authors read and approved the final version of the manuscript.

Conflict of Interest: None.

Funding: Self-funded.

Publication History: Submitted 24 September 2019; Accepted 17 February 2020.

\section{Reference}

1. Brennan G, Shafat A, Mac Donncha C, Vekins C. Lower back pain in physically demanding college academic programs: a questionnaire-based study. BMC Musculoskelet Disord 2007; 8: 67. 
2. Bos E, Krol B, van der Star L, Groothoff J. Risk factors and musculoskeletal complaints in non-specialized nurses, IC nurses, operation room nurses, and X-ray technologists. Int Arch Occup Environ Health 2007; 80: 198-206.

3. Omokhodion FO, Umar US, Ogunnowo BE. Prevalence of low back pain among staff in a rural hospital in Nigeria. Occupational Med 2000; 50: 107-110.

4. Bello B, Adebayo HB. A Systematic Review of the Prevalence of Low Back Pain in Nigeria. Middle East J Rehab Health [Internet] 2017; 4. Available from: http://jrehabilhealth.com/en/articles/1314 6.html

5. Yang H, Haldeman S, Lu M-L, Baker D. Low Back Pain Prevalence and Related Workplace Psychosocial Risk Factors: A Study Using Data From the 2010 National Health Interview Survey. J Manipulative Physiol Ther 2016; 39: 459-472.

6. Saravi BM, Kabirzadeh A, Rezazadeh E, Khariki MF, Asgari Z, Farahabadi EB, et al. Prevalence and Causes of Medical Absenteeism Among Staff (Case Study at Mazandaran University of Medical Sciences: 2009-2010). Mater Sociomed 2013; 25: $233-$ 237.

7. Sikiru L, Hanifa S. Prevalence and risk factors of low back pain among nurses in a typical Nigerian hospital. Afr Health Sci 2010; 10: 26-30.

8. Lagerström M, Hansson $\mathrm{T}$, Hagberg $\mathrm{M}$. Work-related low-back problems in nursing. Scand J Work Environ Health 1998; 24: 449_ 464.

9. Wami SD, Abere G, Dessie A, Getachew D. Work-related risk factors and the prevalence of low back pain among low wage workers: results from a cross-sectional study. BMC Public Health 2019; 19: 1072.
10. O'Sullivan $\mathrm{P}$, Caneiro JP, O'Keeffe M, O'Sullivan K. Unraveling the Complexity of Low Back Pain. J Orthop Sports Phys Ther 2016; 46: 932-937.

11. Awosan KJ, Yikawe SS, Oche OM, Oboirien M. Prevalence, perception and correlates of low back pain among healthcare workers in tertiary health institutions in Sokoto, Nigeria. Ghana Med J 2017; 51: 164-174.

12. Walker BF. The prevalence of low back pain: a systematic review of the literature from 1966 to 1998. J Spinal Disord 2000; 13: 205217.

13. Usman MI, Abubakar MK, Muhammad S, Rabiu A, Garba I. Low Back Pain in Pregnant Women Attending Antenatal Clinic: The Aminu Kano Teaching Hospital Experience. Ann Afr Med 2017; 16: 136-140.

14. Hoy D, Brooks P, Blyth F, Buchbinder R. The Epidemiology of low back pain. Best Pract Res Clin Rheumatol 2010; 24: 769-781.

15. d'Errico A, Viotti S, Baratti A, Mottura B, Barocelli AP, Tagna M, et al. Low back pain and associated presenteeism among hospital nursing staff. J Occup Health 2013; 55: 276283.

16. Punnett L, Prüss-Utün A, Nelson DI, Fingerhut MA, Leigh J, Tak S, et al. Estimating the global burden of low back pain attributable to combined occupational exposures. Am J Ind Med 2005; 48: 459-69.

17. Karahan A, Kav S, Abbasoglu A, Dogan N. Low back pain: prevalence and associated risk factors among hospital staff. J Adv Nurs 2009; 65: 516-524.

18. Sanya AO, Omokhodion FO, Ogwumike OO. Risk factors for Low Back Pain among hospital workers in Ibadan, Oyo State, Nigeria. J Niger Soc Physiother 2009; 15: 3134. 
19. Keriri H. Prevalence and risk factors of low back pain among nurses in operating rooms, Taif, Saudi Arabia. American J Res Communication 2013; 1: 45-70.

20. AlDajah S. Prevalence and risk factors of Low Back Pain among nurses in Sudayr Region. Eur Sci J 2013; 9: 198-205.

21. Cilliers L, Maart S. Attitudes, knowledge and treatment of low back pain amongst nurses in the Eastern Cape, South Africa. Afr J Prim Health Care Fam Med 2013; 5.

22. Lahad A, Malter AD, Berg AO, Deyo RA. The effectiveness of four interventions for the prevention of low back pain. JAMA 1994; 272: 1286-1291.

23. Andersson GB. Epidemiology of low back pain. Acta Orthop Scand Suppl 1998; 281: 28-31.

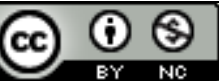

(1)

This is an Open Access document licensed for distribution under the terms and conditions of the Creative Commons Attribution License (http://creativecommons.org/licenses/by-nc/4.0). This permits unrestricted, non-commercial use, reproduction and distribution in any medium provided the original source is adequately cited and credited. 